\title{
ChemComm
}

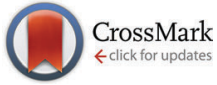

Cite this: Chem. Commun., 2015, 51, 12578

Received 30th March 2015, Accepted 2nd July 2015

DOI: $10.1039 / \mathrm{c5cc02606g}$

www.rsc.org/chemcomm

\section{Cerium-based metal organic frameworks with UiO-66 architecture: synthesis, properties and redox catalytic activity $\dagger$}

\author{
Martin Lammert, ${ }^{a}$ Michael T. Wharmby, ${ }^{\mathrm{b}}$ Simon Smolders, ${ }^{\mathrm{c}}$ Bart Bueken, ${ }^{\mathrm{c}}$ \\ Alexandra Lieb, ${ }^{d}$ Kirill A. Lomachenko, ${ }^{e}$ Dirk De $\operatorname{Vos}^{c}$ and Norbert Stock*a
}

\begin{abstract}
A series of nine $\mathrm{Ce}(\mathrm{IV})$-based metal organic frameworks with the UiO-66 structure containing linker molecules of different sizes and functionalities were obtained under mild synthesis conditions and short reaction times. Thermal and chemical stabilities were determined and a Ce-UiO-66-BDC/TEMPO system was successfully employed for the aerobic oxidation of benzyl alcohol.
\end{abstract}

Metal-Organic Frameworks (MOFs) are potentially porous compounds formed by the linking of inorganic and organic units through coordinative bonding. ${ }^{1}$ They possess highly modular structures, with the possibility to form identical topologies with a variety of different metal cations and organic linker molecules. ${ }^{2}$ So-called reticular synthesis has been extensively applied to yield compounds with tunable and increasingly large pore sizes. ${ }^{3}$ The adjustability and modularity of MOF structures, combined with their porosity suggest applications in a wide range of fields, including gas storage and separation, catalysis and drug delivery. ${ }^{4,5}$

The zirconium-based framework UiO- $66,\left[\mathrm{Zr}_{6} \mathrm{O}_{4}(\mathrm{OH})_{4}(\mathrm{BDC})_{6}\right]$, was first synthesized by solvothermal methods using $\mathrm{ZrCl}_{4}$ as the metal source and 1,4-benzenedicarboxylic acid $\left(\mathrm{H}_{2} \mathrm{BDC}\right)$ as the linker molecule. ${ }^{6}$ During synthesis the $\mathrm{Zr}^{4+}$ cations self-assemble into hexanuclear $\left[\mathrm{Zr}_{6} \mathrm{O}_{4}(\mathrm{OH})_{4}\right]^{12+}$ clusters, which are connected by 12 dicarboxylate linkers to form an expanded cubic close packed framework. ${ }^{6-8}$ A pore network of large octahedral pores $(\sim 11 \AA$ free diameter) and smaller tetrahedral pores $(\sim 8 \AA$ free diameter) is formed, yielding typical specific BET surface areas of $1060-1580 \mathrm{~m}^{2} \mathrm{~g}^{-1}$. $6-9$

\footnotetext{
${ }^{a}$ Institut für Anorganische Chemie, Christian-Albrechts-Universität zu Kiel, Max-Eyth-Straße 2, 24118 Kiel, Germany. E-mail: stock@ac.uni-kiel.de

${ }^{b}$ Diamond Light Source Ltd., Diamond House, Harwell Science \& Innovation Campus, Didcot, Oxfordshire, OX11 ODE, UK. E-mail: michael.wharmby@diamond.ac.uk ${ }^{c}$ Centre for Surface Chemistry and Catalysis, KULeuven, Kasteelpark Arenberg 23, P. O. Box 2461, 3001 Leuven, Belgium. E-mail: dirk.devos@biw.kuleuven.be

${ }^{d}$ Institut für Chemie, Otto-von-Guericke-Universität Magdeburg, Universitätsplatz 2, 39106 Magdeburg, Germany

${ }^{e}$ Department of Chemistry, Turin University, Italy and Southern Federal University, Rostov-on-Don, Russia. E-mail: kirlom@gmail.com

$\dagger$ Electronic supplementary information (ESI) available: Synthesis procedures of MOFs and linker molecules, PXRD patterns, IR spectra, ${ }^{1} \mathrm{H}-\mathrm{NMR}$ measurements, SEM micrographs, Rietveld and Le Bail fits. See DOI: 10.1039/c5cc02606g
}

Extensive computational and experimental studies indicate that the large variability in porosity is caused by defects in the structure, resulting from missing linker molecules. ${ }^{9-11}$ Despite the presence of defects, UiO-66 demonstrates excellent chemical, mechanical and thermal stability. ${ }^{6,11-13}$ Thermal analysis indicates that UiO-66 is stable up to $375{ }^{\circ} \mathrm{C}$ in air, ${ }^{7}$ with the clusters undergoing a reversible dehydration within the range of $250-300{ }^{\circ} \mathrm{C}$. Isoreticular compounds of UiO-66 have also been reported with linear dicarboxylates, ${ }^{6,14-16}$ and squaric acid. ${ }^{17}$ Functionalized derivatives of UiO-66-type compounds, bearing for example $-\mathrm{NH}_{2},-\left(\mathrm{NH}_{2}\right)_{2},-\mathrm{NO}_{2},-\mathrm{Br},-\mathrm{OH},-(\mathrm{OH})_{2}$, $-\mathrm{SO}_{3} \mathrm{H},-\mathrm{COOH},-\mathrm{I},-(\mathrm{SH})_{2}$ are known., ${ }^{9,13,18}$

The tunable porosity and broad range of functionalization of Zr-UiO-66 have led to its study in a wide range of catalytic reactions, ${ }^{19}$ including photocatalysis, ${ }^{20}$ acid-base catalysis ${ }^{21,22}$ whilst the influence of the concentration of defects (i.e. coordinatively unsaturated $\mathrm{Zr}$ sites) has also been investigated. ${ }^{23}$

Complete substitution of zirconium in the structure has also been reported. ${ }^{16,24}$ MOFs containing the hexanuclear $\left[\mathrm{M}_{6} \mathrm{O}_{4}(\mathrm{OH})_{4}\right]^{12+}$ cluster are in fact known for a range of metal(Iv) cations, including Hf, U and Th. ${ }^{25}$ For cerium(Iv), the molecular hexanuclear cluster has been previously reported with sulfate, ${ }^{26}$ acetylacetonate,${ }^{27}$ benzoate ${ }^{28}$ and 1,2-phenyldiphosphonate ions. ${ }^{29}$ To the best of our knowledge only one cerium(rv)-based MOF has been reported in recent years, ${ }^{30}$ but did not contain this hexanuclear cluster.

Here we report our successful determination of the conditions to stabilize the $\left[\mathrm{Ce}_{6} \mathrm{O}_{4}(\mathrm{OH})_{4}\right]^{12+}$ cluster during MOF formation and the synthesis of a range of UiO-66-like frameworks with different pore sizes and functionalities. Reaction of cerium(Iv) ammonium nitrate $\left(\left(\mathrm{NH}_{4}\right)_{2} \mathrm{Ce}\left(\mathrm{NO}_{3}\right)_{6}\right)$ with fumaric acid $\left(\mathrm{H}_{2} \mathrm{Fum}\right)$, 1,4-benzenedicarboxylic acid $\left(\mathrm{H}_{2} \mathrm{BDC}\right)$, 2,6-naphthalenedicarboxylic acid $\left(\mathrm{H}_{2} \mathrm{NDC}\right)$ and 4,4'-biphenyldicarboxylic acid $\left(\mathrm{H}_{2} \mathrm{BPDC}\right)$ leads to the formation of isoreticular MOFs with the UiO-66-type structure (Fig. 1). For all the different linkers, reactions were performed under the same conditions in Pyrex glass reactions tubes. Through careful optimization of the reaction conditions (see ESI $\dagger$ ), it was found that short reaction times (15 min) with conventional heating at $100{ }^{\circ} \mathrm{C}$ and stirring gave the most phase pure products. 


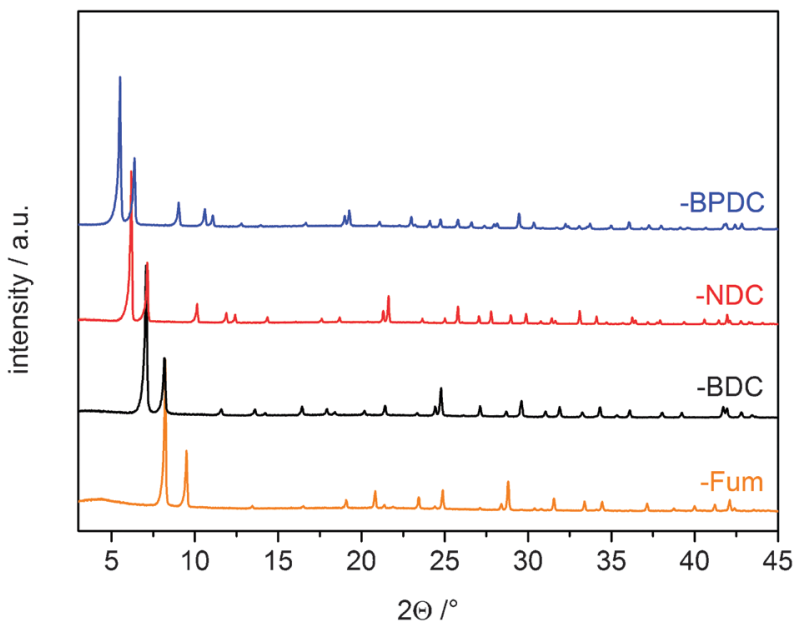

Fig. 1 PXRD patterns of Ce-UiO-66-BDC, -Fum, -NDC and-BPDC.

All compounds were obtained as microcrystalline powders; therefore structures were confirmed from PXRD data. The structures of Ce-UiO-66-Fum and -BDC were confirmed by Rietveld refinement (Table 1, Fig. S1 and S2, ESI $\dagger$ ). Ce-UiO-66-BDC and -Fum exhibit structures isoreticular with their $\mathrm{Zr}$ analogues ${ }^{6,14}$ and crystallize in the space group $F m \overline{3} m$ and $P n \overline{3}$, respectively (Fig. 1 and Fig. S5, ESI $\dagger$ ). In Ce-UiO-66-BDC the $\left[\mathrm{Ce}_{6} \mathrm{O}_{4}(\mathrm{OH})_{4}\right]^{12+}$ clusters are organized in a cubic close-packed arrangement and bridged by twelve different $\mathrm{BDC}^{2-}$ molecules, to give the structural formula $\left[\mathrm{Ce}_{6} \mathrm{O}_{4}(\mathrm{OH})_{4}(\mathrm{BDC})_{6}\right]$ (Fig. S3, ESI $\dagger$ ). SEM measurements of the particle morphology of Ce-UiO-66-BDC showed that the compound forms as agglomerates of mostly spherical particles, with diameters in the range of 100-500 nm (Fig. S4, ESI + ). Unit cells of Ce-UiO-66NDC and -BPDC were confirmed by Le Bail profile fitting (Fig. S6 and S7, ESI†). Crystallographic details for all four compounds are given in the ESI $\dagger$ (Table S1). $\neq$

The oxidation state of cerium in Ce-UiO-66-BDC was determined by XANES spectroscopy (Fig. 2). $\mathrm{L}_{\mathrm{III}}$-edge XANES features typical for $\mathrm{Ce}$ (III) are significantly different from those of $\mathrm{Ce}(\mathrm{IV})$. $\mathrm{Ce}(\mathrm{III})$ displays a very intense single peak (around $5726 \mathrm{eV}$ ), whereas Ce(rv) exhibits two well-separated maxima of lower intensity (around 5729 and $5739 \mathrm{eV}){ }^{31}$ The XANES spectra unambiguously demonstrate that Ce-UiO-66-BDC contains Ce(Iv) without any detectable trace of Ce(III).

The synthesis of functionalized phase-pure samples of Ce-UiO66-BDC-X ( $\left.\mathrm{X}=\mathrm{F}, \mathrm{CH}_{3}, \mathrm{Cl}, \mathrm{NO}_{2}, \mathrm{COOH}\right)$ was accomplished under

Table 1 Crystallographic data of Ce-UiO-66-BDC and -Fum

\begin{tabular}{lll}
\hline Ce-UiO-66 & -Fum & -BDC \\
\hline Formula Sum & {$\left[\mathrm{Ce}_{6} \mathrm{O}_{4}(\mathrm{OH})_{4}(\mathrm{Fum})_{6}\right]$} & {$\left[\mathrm{Ce}_{6} \mathrm{O}_{4}(\mathrm{OH})_{4}(\mathrm{BDC})_{6}\right]$} \\
Wavelength & $\mathrm{CuK}_{1}$ & $\mathrm{CuK \alpha} \alpha_{1}$ \\
$a / \AA$ & $18.5728(2)$ & $21.4727(3)$ \\
Volume $/ \AA^{3}$ & $6406.4(2)$ & $9900.6(4)$ \\
Spacegroup & $P n \overline{3}$ & $F m \overline{3} m$ \\
$R_{\text {wp }} / \%$ & 5.05 & 2.65 \\
$R_{\text {Bragg }} \%$ & 1.62 & 5.86 \\
GoF & 1.180 & 2.268 \\
No. of atoms & 16 & 6 \\
No. of restraints & 23 & 18 \\
No. of parameters & 72 & 69
\end{tabular}

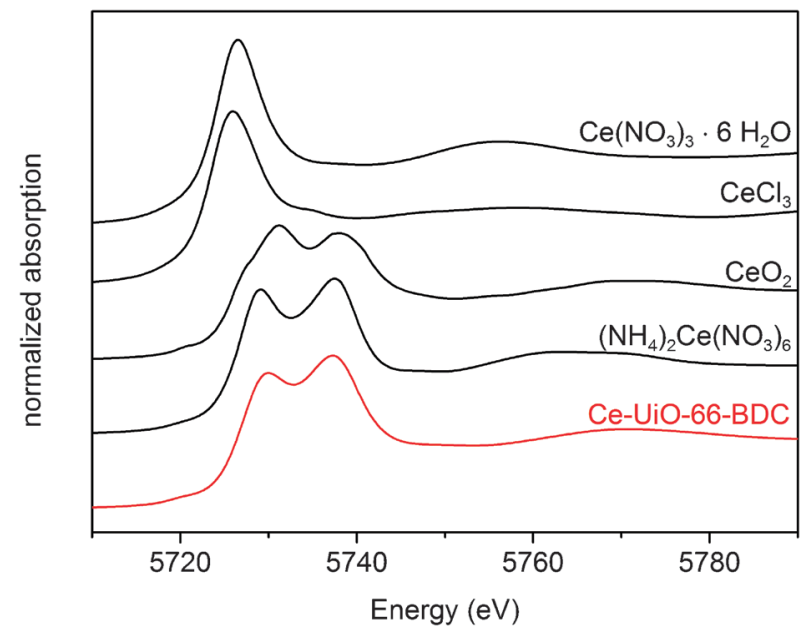

Fig. 2 Ce LIII XANES spectra of Ce-UiO-66-BDC and of Ce(III) and Ce(Iv) model compounds.

identical synthetic conditions as those used for the Ce-UiO-66-BDC. The PXRD patterns and the lattice parameters as determined by Le Bail fitting in the space group $F m \overline{3} m$ are presented in Fig. S8-S13 and Table S2 (ESI $\dagger$ ).

Chemical stability of Ce-UiO-66-BDC was proven by stirring in different solvents for $24 \mathrm{~h}$ at room temperature. The compound is stable in a variety of organic solvents as well as in water, although some peak broadening was observed. Ce-UiO-66-BDC decomposes only in acidic $(2 \mathrm{M} \mathrm{HCl})$ and basic $(2 \mathrm{M} \mathrm{NaOH})$ media (Fig. S14, ESI $\dagger$ ). Ce-UiO-66-Fum is similarly stable in organic solvents, though it is more susceptible to degradation (Fig. S15, ESI $\dagger$ ). The longer linker containing Ce-UiO-66-NDC and -BPDC are stable in aprotic organic solvents. However in water, ethanol and under air both compounds show a slow continuous loss of intensity in the diffraction pattern. Interestingly, it was possible to recover the crystallinity of the compounds by heating in $1 \mathrm{ml}$ DMF for $5 \mathrm{~min}$ at $100{ }^{\circ} \mathrm{C}$, with crystallinity confirmed by PXRD measurements (Fig. S16 and S17, ESI†).

Ce-UiO-66-BDC collapses on heating above $300{ }^{\circ} \mathrm{C}$, with a weight loss of $30.3 \mathrm{wt} \%$. This framework collapse is clearly observed in the VT-PXRD data (Fig. S19 and S20, ESI $\dagger$ ), with few changes occurring in the diffraction patterns over the range $40-240{ }^{\circ} \mathrm{C}$; from $320-520{ }^{\circ} \mathrm{C}$ the reflections broaden dramatically to result in a rather amorphous final product. The observed weight loss of framework collapse is $4 \mathrm{wt} \%$ lower than expected (expected $34.2 \mathrm{wt} \%$ ); this discrepancy is attributed to structural defects, arising from missing BDC linker molecules, as previously reported for $\mathrm{Zr}$ containing UiO-66. ${ }^{7,10,11}$ Based on the TGA results, it is assumed that on average the $\left[\mathrm{Ce}_{6} \mathrm{O}_{4}(\mathrm{OH})_{4}\right]^{12+}$ clusters are coordinated by 11 linkers instead of 12 .

Ce-UiO-66-Fum was also studied by TGA and shows a similar pattern of weight losses (Fig. S21, ESI $\dagger$ ). Decomposition occurs at a significantly lower temperature than for the Ce-UiO-66-BDC compound and also the reported Zr-Fum. ${ }^{14}$ TGA studies have also been performed on the functionalized Ce-UiO-66-BDC-X compounds. The $-\mathrm{NO}_{2}$ functionalized compound is approximately as stable as the analogous unfunctionalized compound (Fig. S22, ESI $\dagger$ ), 
Table 2 Specific surface areas and micropore volumes of Ce-UiO-66BDC, Ce-UiO-66-BDC- $\mathrm{X}$ derivatives and $\mathrm{Ce}-\mathrm{UiO}-66$-Fum

\begin{tabular}{lll}
\hline Compound & $S_{\text {BET }}\left[\mathrm{m}^{2} \mathrm{~g}^{-1}\right]$ & $V_{\text {micro }}\left[\mathrm{cm}^{3} \mathrm{~g}^{-1}\right]$ \\
\hline Ce-UiO-66-BDC & 1282 & 0.50 \\
Ce-UiO-66-BDC-F & 1075 & 0.42 \\
Ce-UiO-66-BDC-CH & 985 & 0.39 \\
Ce-UiO-66-BDC-Cl & 770 & 0.31 \\
Ce-UiO-66-BDC-NO & & 0.29 \\
Ce-UiO-66-Fum & 727 & 0.30
\end{tabular}

however compounds bearing other functionalities showed significantly lower stability.

Solution ${ }^{1} \mathrm{H}$-NMR was used to confirm the incorporation of the functionalized terephthalate linkers without modification to their functional groups (Fig. S25-S31, ESI $\dagger$ ). $\mathrm{N}_{2}$ sorption measurements were performed to evaluate the porosity of the Ce-UiO-66 compounds. The results are presented in Table 2 and Fig. S32 and S33 (ESI $\dagger$ ). All sorption isotherms show the characteristic Type I adsorption isotherm curve shape. ${ }^{32}$ Ce-UiO-66-BDC has a specific BET surface area of $1282 \mathrm{~m}^{2} \mathrm{~g}^{-1}$. We expect Ce-UiO-66-BDC to exhibit a smaller specific BET surface area than Zr-UiO-66, since Ce is approx. $50 \%$ heavier than $\mathrm{Zr}$. Thus, compared with a specific surface area for defect rich Zr-UiO-66 reported as $1580 \mathrm{~m}^{2} \mathrm{~g}^{-1}, 9$ it seems likely that the relatively high surface area of Ce-UiO-66-BDC results from the presence of missing linker molecules, in agreement with the observations from the TGA study. Ce-UiO-66-Fum has a specific BET surface area of $732 \mathrm{~m}^{2} \mathrm{~g}^{-1}$. This value is in accordance with the BET surface area reported for the analogous Zr-fumarate $\left(856 \mathrm{~m}^{2} \mathrm{~g}^{-1}\right) .{ }^{14}$ Sorption isotherms for Ce-UiO-66-NDC and -BPDC could not be measured as both compounds decompose during activation under reduced pressure, even at temperatures as low as $100{ }^{\circ} \mathrm{C}$. The $\mathrm{N}_{2}$ sorption isotherms of the functionalized Ce-UiO-66-BDC-X ( $\mathrm{X}=\mathrm{F}, \mathrm{CH}_{3}, \mathrm{Cl}, \mathrm{NO}_{2}$ ) show a decrease in the specific BET surface area with increasing weight and size of the functional group (Table S3 and Fig. S33, ESI $\dagger$ ). For Ce-UiO-66BDC-COOH no $\mathrm{N}_{2}$ sorption isotherm could be obtained, because the compound decomposes during activation at $100{ }^{\circ} \mathrm{C}$.

PXRD patterns collected after the $\mathrm{N}_{2}$ sorption experiments indicate that all other samples remain intact after activation, although for Ce-UiO-66-Fum and -BDC-Cl some peak broadening was observed (Fig. S34, ESI $\dagger$ ).

Given the well-known redox chemistry of cerium oxides, ${ }^{33}$ and more specifically the previously reported stoichiometric oxidation of 1,4-benzenediol with a similar hexanuclear Ce-benzoate cluster, ${ }^{28}$ we tested Ce-UiO-66-BDC as a catalyst in the aerobic oxidation of benzyl alcohol (Scheme 1 and Table 3).

Using only Ce-UiO-66-BDC activated at $180{ }^{\circ} \mathrm{C}$, a modest yield of $8 \%$ benzaldehyde was achieved, which is significantly more than for the uncatalyzed blank reaction $(2 \%)$ or for the reaction employing nanoparticulate $\mathrm{CeO}_{2}(7 \%)$. Based on existing literature combining<smiles>OCc1ccccc1</smiles>

$$
\underset{6 \text { bar } \mathrm{O}_{2}, \mathrm{CH}_{3} \mathrm{CN}, 110^{\circ} \mathrm{C}, 24 \mathrm{~h}}{\stackrel{10 \mathrm{~mol} \% \mathrm{Ce}, 30 \mathrm{~mol} \% \mathrm{TEMPO}}{\longrightarrow}}
$$<smiles>O=Cc1ccccc1</smiles>

Scheme 1 Aerobic oxidation of benzyl alcohol.
$\left(\left(\mathrm{NH}_{4}\right)_{2} \mathrm{Ce}\left(\mathrm{NO}_{3}\right)_{6}\right)$ and TEMPO (2,2,6,6-tetramethylpiperidin-1-yl)oxyl as a co-catalyst, ${ }^{34}$ we devised an analogous system with Ce-UiO-66BDC. Addition of TEMPO to Ce-UiO-66-BDC resulted in a benzyl alcohol conversion of $29 \%$. Upon raising the activation temperature of the framework to $220{ }^{\circ} \mathrm{C}$, a strong increase in activity was observed, with $88 \%$ conversion of benzyl alcohol and complete selectivity to benzaldehyde. No benzoic acid formation was found via GC-MS of the silylated reaction mixture. The marked influence of the activation temperature is attributed to the removal of strongly adsorbed guest molecules and possible cluster dehydration as evidenced from the TGA data (Fig. S18, ESI $\dagger$ ), creating open coordination sites analogous to the situation in Zr-UiO-66-BDC. A reaction using only TEMPO as catalyst resulted in a benzaldehyde yield of 7\%, clearly indicating a synergetic effect between Ce-UiO-66BDC and TEMPO. Strikingly, such a synergism is not observed at all between Zr-UiO-66-BDC and TEMPO (see Table 3). Finally, Ce-UiO66-BDC proved stable under the applied reaction conditions, as evidenced by PXRD. ICP analysis determined the amount of Ce in solution to approximately $2 \mathrm{ppm}$, which together with a hotfiltration test further proves the heterogenous nature of the reaction (Fig. S39 and S40, ESI $\dagger$ ).

To gain some mechanistic insight, the reaction was performed in absence of $\mathrm{O}_{2}\left(\mathrm{~N}_{2}\right.$ atmosphere), and only a low benzaldehyde yield of $11 \%$ was found. In such conditions, a buildup of 1-hydroxy2,2,6,6-tetramethylpiperidine (TEMPOH), the reduction product of TEMPO, was detected by GC-MS, with $\sim 40 \%$ of the original TEMPO being converted to TEMPOH (Fig. S35 and S36, ESI $\dagger$ ). ${ }^{35}$ Under $\mathrm{O}_{2}$, only $3 \%$ of the initial TEMPO is found as TEMPOH, as the latter is prone to a fast reoxidation to TEMPO. From these observations, we propose a basic catalytic cycle (Fig. S37, ESI $\dagger$ ). First, TEMPO undergoes a one-electron oxidation at the surface of Ce-UiO-66-BDC to form its oxoammonium counterpart, with a concomitant reduction of $\mathrm{Ce}^{4+}$ to $\mathrm{Ce}^{3+}$. Due to its size, TEMPO is unable to enter the pores of Ce-UiO-66-BDC, as was verified by additional adsorption experiments (Fig. S38, ESI $\dagger$ ), leaving only $\mathrm{Ce}^{4+}$ close to the particle surface available for oxidation. The oxoammonium species reacts with the alcohol to form the aldehyde while being reduced to TEMPOH. ${ }^{36}$ The latter spontaneously

Table 3 Aerobic oxidation of benzyl alcohol

\begin{tabular}{|c|c|c|}
\hline Catalytic system & Catalyst activation temp. $\left[{ }^{\circ} \mathrm{C}\right]$ & $X_{\mathrm{bOH}}(\%)$ \\
\hline Blank $^{a}$ & n.a. & 2 \\
\hline Ce-UiO-66-BDC & 180 & 8 \\
\hline Ce-UiO-66-BDC/TEMPO & 180 & 29 \\
\hline Ce-UiO-66-BDC/TEMPO & 220 & 88 \\
\hline Ce-UiO-66-BDC/TEMPO ${ }^{b}$ & 220 & 7 \\
\hline Ce-UiO-66-NDC/TEMPO & 180 & 80 \\
\hline Zr-UiO-66-BDC & 180 & 2 \\
\hline Zr-UiO-66-BDC/TEMPO & 220 & 8 \\
\hline Zr-UiO-66-BDC/TEMPO & 220 & 11 \\
\hline$\left(\left(\mathrm{NH}_{4}\right)_{2} \mathrm{Ce}\left(\mathrm{NO}_{3}\right)_{6}\right) / \mathrm{TEMPO}^{c}$ & n.a. & 75 \\
\hline TEMPO & n.a. & 7 \\
\hline $\mathrm{CeO}_{2}{ }^{d}$ & n.a. & 7 \\
\hline $\mathrm{CeO}_{2} / \mathrm{TEMPO}$ & n.a. & 15 \\
\hline
\end{tabular}

$X_{\mathrm{bOH}}=$ benzyl alcohol conversion; 6 bar $\mathrm{O}_{2}, 110{ }^{\circ} \mathrm{C}, 24 \mathrm{~h}, \mathrm{CH}_{3} \mathrm{CN}$, $1.67 \mathrm{~mol} \%$ Ce/Zr-UiO-66, $30 \mathrm{~mol} \%$ TEMPO, 7 h. ${ }^{a} 64 \mathrm{~h}$ reaction time. ${ }^{b} 6$ bar $\mathrm{N}_{2} .{ }^{c} 1 \mathrm{~mol} \%\left(\left(\mathrm{NH}_{4}\right)_{2} \mathrm{Ce}\left(\mathrm{NO}_{3}\right)_{6}\right), 15 \mathrm{~mol} \%$ TEMPO. ${ }^{d} 10 \mathrm{~mol} \%$ $\mathrm{CeO}_{2}$ (see Fig. S41, ESI). 
oxidizes back to TEMPO under $\mathrm{O}_{2}$, but could alternatively react with an oxoammonium cation to form two TEMPO molecules. Finally, we hypothesize that reoxidation of $\mathrm{Ce}^{3+}$ by dioxygen regenerates the MOF co-catalyst. Using longer linkers is a viable option to increase the catalytic activity by allowing the reactants access to the internal pore voids. This is shown by the conversion increase from 29 to $80 \%$ for respectively BDC and 2,6-naphthalenedicarboxylate based materials, both activated in air at $180{ }^{\circ} \mathrm{C}$.

In summary, we have demonstrated the successful synthesis of an isoreticular series of porous cerium based MOFs with the UiO-66-type framework. Conditions were identified which favored the self-assembly of the $\left[\mathrm{Ce}_{6} \mathrm{O}_{4}(\mathrm{OH})_{4}\right]^{12+}$ cluster and using these conditions UiO-66-type compounds containing linkers of different length as well as functionalized linker molecules were obtained. XANES experiments unambiguously proved the presence of $\mathrm{Ce}^{4+}$ ions. Ce-UiO-66-BDC shows the highest chemical and thermal stability and initial experiments revealed it can be used as a co-catalyst with TEMPO in alcohol oxidations. Further investigations are currently being carried out to extend the number of Ce-based MOFs to other topologies, to get a deeper understanding of the catalytic process and to study the properties of the Ce-UiO-66type MOFs in other catalytic reactions.

We acknowledge the support of Bordiga, Braglia, Bouchevreau, Lamberti, and Lillerud, for the collection of the XANES spectra in Lund. The travel to Lund of Lamberti and Lomachenko was supported by the Russian Mega-grant No. 14.Y26.31.0001.

\section{Notes and references}

\# Crystallographic data for the structural analysis have been deposited with the Cambridge Crystallographic Data Centre (CCDC 10369031036904).

1 O. M. Yaghi, M. O'Keeffe, N. W. Ockwig, H. K. Chae, M. Eddaoudi and J. Kim, Nature, 2003, 423, 705-714; S. Kitagawa, R. Kitaura and S. Noro, Angew. Chem., Int. Ed., 2004, 43, 2334-2375; G. Férey, Chem. Soc. Rev., 2008, 37, 191-214; D. Farrusseng, Metal-Organic Frameworks, Wiley-VCH, Weinheim, 2011.

2 M. T. Wharmby, G. M. Pearce, J. P. S. Mowat, J. M. Griffin, S. E. Ashbrook, P. A. Wright, L.-H. Schilling, A. Lieb, N. Stock, S. Chavan, S. Bordiga, E. Garcia, G. D. Pirngruber, M. Vreeke and L. Gora, Microporous Mesoporous Mater., 2012, 157, 3-17; R. Banerjee, A. Phan, B. Wang, C. Knobler, H. Furukawa, M. O'Keeffe and O. M. Yaghi, Science, 2008, 319, 939-943.

3 H. Deng, S. Grunder, K. E. Cordova, C. Valente, H. Furukawa, M. Hmadeh, F. Gándara, A. C. Whalley, Z. Liu, S. Asahina, H. Kazumori, M. O'Keeffe, O. Terasaki, J. F. Stoddart and O. M. Yaghi, Science, 2012, 336, 1018-1023; H. Reinsch, S. Waitschat and N. Stock, Dalton Trans., 2013, 42, 4840-4847.

4 J. R. Long and O. M. Yaghi, Chem. Soc. Rev., 2009, 38, 1201-1508(ed.).

5 H. Furukawa, K. E. Cordova, M. O'Keeffe and O. M. Yaghi, Science, 2013, 341, 1230444.

6 J. H. Cavka, S. Jakobsen, U. Olsbye, N. Guillou, C. Lamberti, S. Bordiga and K. P. Lillerud, J. Am. Chem. Soc., 2008, 130, 13850-13851.

7 L. Valenzano, B. Civalleri, S. Chavan, S. Bordiga, M. H. Nilsen, S. Jakobsen, K. P. Lillerud and C. Lamberti, Chem. Mater., 2011, 23, 1700-1718.

8 F. Ragon, P. Horcajada, H. Chevreau, Y. K. Hwang, U. H. Lee, S. R. Miller, T. Devic, J.-S. Chang and C. Serre, Inorg. Chem., 2014, 53, 2491-2500.

9 M. J. Katz, Z. J. Brown, Y. J. Colon, P. W. Siu, K. A. Scheidt, R. Q. Snurr, J. T. Hupp and O. K. Farha, Chem. Commun., 2013, 49, 9449-9451.
10 H. Wu, Y. S. Chua, V. Krungleviciute, M. Tyagi, P. Chen, T. Yildirim and W. Zhou, J. Am. Chem. Soc., 2013, 135, 10525-10532.

11 G. C. Shearer, S. Chavan, J. Ethiray, J. G. Vitillo, S. Svelle, U. Olsbye, C. Lamberti, S. Bordiga and K. P. Lillerud, Chem. Mater., 2014, 26, 4068-4071.

12 J. B. DeCoste, G. W. Peterson, H. Jasuja, T. G. Glover, Y. Huang and K. S. Walton, J. Mater. Chem. A, 2013, 1, 5642-5650.

13 M. Kandiah, M. H. Nilsen, S. Usseglio, S. Jakobsen, U. Olsbye, M. Tilset, C. Larabi, E. A. Quadrelli, F. Bonino and K. P. Lillerud, Chem. Mater., 2010, 22, 6632-6640.

14 G. Wißmann, A. Schaate, S. Lilienthal, I. Bremer, A. M. Schneider and P. Behrens, Microporous Mesoporous Mater., 2012, 152, 64-70.

15 V. Guillerm, S. Gross, C. Serre, T. Devic, M. Bauer and G. Ferey, Chem. Commun., 2010, 46, 767-769.

16 V. Bon, I. Senkovska, M. S. Weiss and S. Kaskel, CrystEngComm, 2013, 15, 9572-9577.

17 B. Bueken, H. Reinsch, N. Reimer, I. Stassen, F. Vermoortele, R. Ameloot, N. Stock, C. E. A. Kirschhock and D. E. De Vos, Chem. Commun., 2014, 50, 10055-10058.

18 S. Biswas, J. Zhang, Z. Li, Y.-Y. Liu, M. Grzywa, L. Sun, D. Volkmer and P. Van Der Voort, Dalton Trans., 2013, 42, 4730-4737; M. Lin Foo, S. Horike, T. Fukushima, Y. Hijikata, Y. Kubota, M. Takata and S. Kitagawa, Dalton Trans., 2012, 41, 13791-13794; S. J. Garibay and S. M. Cohen, Chem. Commun., 2010, 46, 7700-7702; K.-K. Yee, N. Reimer, J. Liu, S.-Y. Cheng, S.-M. Yiu, J. Weber, N. Stock and Z. Xu, J. Am. Chem. Soc., 2013, 135, 7795-7798.

19 F. Vermoortele, M. Vandichel, B. Van de Voorde, R. Ameloot, M. Waroquier, V. Van Speybroeck and D. E. De Vos, Angew. Chem., 2012, 124, 4971-4974.

20 C. Gomes Silva, I. Luz, F. X. Llabrés i Xamena, A. Corma and H. García, Chem. - Eur. J., 2010, 16, 11133-11138.

21 F. Vermoortele, R. Ameloot, A. Vimont, C. Serre and D. De Vos, Chem. Commun., 2011, 47, 1521-1523.

22 M. N. Timofeeva, V. N. Panchenko, J. W. Jun, Z. Hasan, M. M. Matrosova and S. H. Jhung, Appl. Catal., A, 2013, 471, 91-97.

23 F. Vermoortele, B. Bueken, G. Le Bars, B. Van de Voorde, M. Vandichel, K. Houthoofd, A. Vimont, M. Daturi, M. Waroquier, V. Van Speybroeck, C. Kirschhock and D. E. De Vos, J. Am. Chem. Soc., 2013, 135, 11465-11468.

24 S. Jakobsen, D. Gianolio, D. S. Wragg, M. H. Nilsen, H. Emerich, S. Bordiga, C. Lamberti, U. Olsbye, M. Tilset and K. P. Lillerud, Phys. Rev. B: Condens. Matter Mater. Phys., 2012, 86, 125429; C. Falaise, C. Volkringer, J.-F. Vigier, N. Henry, A. Beaurain and T. Loiseau, Chem. - Eur. J., 2013, 19, 5324-5331; C. Falaise, J. S. Charles, C. Volkringer and T. Loiseau, Inorg. Chem., 2015, 54, 2235-2242.

25 N. N. Greenwood and A. Earnshaw, Chemistry of the Elements, Elsevier Ltd, Oxford, 2nd edn, 1997.

26 G. Lungren, Recl. Trav. Chim. Pays-Bas, 1956, 75, 585-588.

27 P. Toledano, F. Ribot and C. Sanchez, C. R. Seances Acad. Sci., Ser. 2, 1990, 311, 1315.

28 R. Das, R. Sarma and J. B. Baruah, Inorg. Chem. Commun., 2010, 13, 793-795.

29 J. Diwu, J. J. Good, V. H. DiStefano and T. E. Albrecht-Schmitt, Eur. J. Inorg. Chem., 2011, 1374-1377.

30 F. Costantino, P. L. Gentili and N. Audebrand, Inorg. Chem. Commun., 2009, 12, 406-408.

31 A. V. Soldatov, T. S. Ivanchenko, S. Della Longa, A. Kontani, Y. Iwamoto and A. Bianconi, Phys. Rev. B, 1994, 50, 5074-5080.

32 F. Rouquerol, J. Rouquerol and K. S. W. Sing, Adsorption by Powders and Porous Solids: Principles, Methodology and Applications, Academic Press, New York, 1998.

33 A. Trovarelli, Catal. Rev.: Sci. Eng., 1996, 38, 439-520.

34 V. Sridharan and J. C. Menéndez, Chem. Rev., 2010, 110, 3805-3849; S. S. Kim and H. C. Jung, Synthesis, 2003, 2135-2137.

35 H. Henry-Riyad and T. T. Tidwell, J. Phys. Org. Chem., 2003, 16, 559-563.

36 Z. Ma and J. M. Bobbitt, J. Org. Chem., 1991, 56, 6110-6114; A. E. J. De Nooy, A. C. Besemer and H. Van Bekkum, Synthesis, 1996, 1153-1176; R. A. Sheldon, I. W. C. E. Arends, G.-J. Ten Brink and A. Dijksman, Acc. Chem. Res., 2002, 35, 774-781; W. F. Bailey and J. M. Bobbitt, J. Org. Chem., 2007, 72, 4504-4509. 